\title{
Obesity and Women's Health: An Evidence-Based Review
}

\author{
Teresa Kulie, MD, Andrew Slattengren, DO, Jackie Redmer MD, MPH, \\ Helen Counts, MD, Anne Eglash, MD, and Sarina Schrager MD, MS
}

\begin{abstract}
Obesity negatively impacts the health of women in many ways. Being overweight or obese increases the relative risk of diabetes and coronary artery disease in women. Women who are obese have a higher risk of low back pain and knee osteoarthritis. Obesity negatively affects both contraception and fertility as well. Maternal obesity is linked with higher rates of cesarean section as well as higher rates of highrisk obstetrical conditions such as diabetes and hypertension. Pregnancy outcomes are negatively affected by maternal obesity (increased risk of neonatal mortality and malformations). Maternal obesity is associated with a decreased intention to breastfeed, decreased initiation of breastfeeding, and decreased duration of breastfeeding. There seems to be an association between obesity and depression in women, though cultural factors may influence this association. Obese women are at higher risk for multiple cancers, including endometrial cancer, cervical cancer, breast cancer, and perhaps ovarian cancer. (J Am Board Fam Med 2011;24:75-85.)
\end{abstract}

Keywords: Evidence-based, Obesity, Women's Health

The prevalence of obesity is rising. The World Health Organization estimates that more than 1 billion people are overweight, with 300 million meeting the criteria for obesity. ${ }^{1}$ Twenty-six percent of nonpregnant women ages 20 to 39 are overweight and $29 \%$ are obese. ${ }^{2}$ This article will review the wide-ranging effects that obesity has on both reproductive health and chronic medical conditions in women.

A PubMed search was performed using the key words "obesity," "overweight," "body mass index" (BMI), "gender," "women's health," and the condition reviewed. The most recent evidence-based articles were included in the review. The evidence level of each article was determined by the authors based on the type of study, randomization, the number of participants, and loss to follow-up.

This article was externally peer reviewed.

Submitted 24 March 2010; revised 12 July 2010; accepted 19 July 2010.

From Department of Family Medicine, University of Wisconsin, Madison.

Funding: none.

Conflict of interest: none declared.

Corresponding author: Sarina Schrager, MD, MS, Department of Family Medicine, University of Wisconsin, $777 \mathrm{~S}$. Mills St., Madison, WI 53715 (E-mail: sbschrag@wisc.edu).
Table 1 provides a classification for overweight and obesity based on BMI. ${ }^{3}$ Waist circumference can also be used to classify overweight and obesity. In women, a waist circumference of $>35$ inches $(88$ $\mathrm{cm})$ is high risk, whereas in men the level is $>40$ inches $(102 \mathrm{~cm})$. Research varies in the measurements of obesity used to classify participants in each study.

\section{Obesity and Type 2 Diabetes Mellitus}

The risk of diabetes mellitus (DM) increases with the degree and duration of being overweight or obese and with a more central or visceral distribution of body fat. Increased visceral fat enhances the degree of insulin resistance associated with obesity. ${ }^{4}$ In turn, insulin resistance and increased visceral fat are the hallmarks of metabolic syndrome, an assembly of risk factors for developing diabetes and cardiovascular disease. $^{4-6}$

The Nurses' Health Study followed 84,000 female nurses for 16 years and found that being overweight or obese was the single most important predictor of $\mathrm{DM}^{7}$ An increased risk of DM was seen in women with BMI values $>24$ and a waistto-hip ratio $>0.76 .^{8}$ After adjusting for age, family history of diabetes, smoking, exercise, and several 
Table 1. Classification of Obesity Based on Body Mass Index (BMI) ${ }^{3}$

\begin{tabular}{lc}
\hline Classification & BMI \\
\hline Underweight & $<18.5$ \\
Normal Weight & $18.5-24.9$ \\
Overweight & $25.0-29.9$ \\
Obese & \\
Class I & $30.0-34.9$ \\
Class II & $35-39.9$ \\
Class III* & $>40$ \\
\hline
\end{tabular}

*Morbid obesity or extreme obesity.

dietary factors, the relative risk (RR) of DM for the 90th percentile $(B M I=29.9)$ versus the 10 th percentile $(\mathrm{BMI}=20.1)$ was $11.2(95 \% \mathrm{CI}, 7.9-15.9) .{ }^{5}$ A recent meta-analysis similarly found a pooled RR for developing DM of 12.41 (95\% CI, 9.03-17.06) among obese women. ${ }^{9}$

In morbidly obese patients (BMI $>40$ or $>35$ with major comorbidities), weight loss surgery can be considered if conservative measures fail. ${ }^{5}$ In one Swedish study, $68 \%$ of obese patients with DM who underwent gastric bypass surgery and subsequently lost weight went into remission. ${ }^{4} \mathrm{~A}$ systematic review that included more than $135,000 \mathrm{pa}-$ tients ( $80 \%$ women) found that bariatric surgery resulted in complete resolution of diabetes in $78 \%$ of patients and improvement in diabetic control in more than $86 \%$ of patients. ${ }^{10}$ These patients had improvements in insulin levels, fasting glucose levels, and glycosylated hemoglobin levels. ${ }^{10}$

\section{Obesity and Coronary Artery Disease}

Obesity is an independent risk factor for the development of coronary artery disease (CAD) in women and is an important modifiable risk factor for prevention of CAD. ${ }^{11}$ The mechanism of action is likely the relationship between obesity and insulin resistance. In a large cohort study of 37,000 women in Washington state, women with a BMI $\geq 35$ had an odds ratio (OR) of 2.7 for CAD and an OR of 5.4 for hypertension. ${ }^{12}$

Abdominal obesity may be more harmful in women than BMI or weight alone. Waist circumference is an independent risk factor for developing $\mathrm{CAD}$ in both normal-weight women and overweight women. ${ }^{11}$ The Interheart global case-control study of 6787 women from 52 countries found that abdominal obesity was more predictive of myocardial infarction than was BMI alone. ${ }^{13}$ A prospective cohort study of more than 44,000 women in the Nurses Health Study found an association between having a waist circumference of $>88 \mathrm{~cm}$ and the risk of cardiovascular mortality. Women with a waist circumference of $>88 \mathrm{~cm}$ had a RR of death from cardiovascular disease of 3.02 (95\% CI, 1.31-6.99). ${ }^{8}$ Waist-to-hip ratio is another significant predictor of death from cardiovascular disease, with a RR of 3.45 (95\% CI, 2.02 to 6.92 ) in women with a ratio of $>0.88 .{ }^{14}$

A meta-analysis that included data on more than 22,000 patients ( $72 \%$ women) looking at the relationship between bariatric surgery and cardiovascular risk factors found that hyperlipidemia improved in $70 \%$ of patients after surgery and hypertension was resolved in $62 \%$ and improved in $78 \% .^{15}$

\section{Obesity and Musculoskeletal Pain}

In the United States, the Center for Disease Control and Prevention statistics show that more than $31 \%$ of obese adults reported a doctor diagnosis of arthritis compared with only $16 \%$ of nonobese adults. ${ }^{16}$ Obesity has been implicated in the development or progression of low back pain and knee osteoarthritis $(\mathrm{OA})$ in women.

The mechanism by which obesity causes lumbar back pain is poorly understood, but the contribution of both mechanical and system factors is likely. ${ }^{17}$ Direct mechanical stress on the intervertebral discs and the indirect effects of atherosclerosis on blood flow to the lumbar spine are suspected to be mechanisms through which obesity affects the discs, leading to subsequent low back pain. Further research to elucidate the exact mechanism is needed. ${ }^{18}$

Obesity at age 23 increases the risk of low back pain onset for women within 10 years ${ }^{19}$ (Table 2). The increased burden of obesity is more obvious as women age, with significantly more obese women over the age of 40 reporting low back pain and lumbosacral radicular symptoms. ${ }^{23}$ These symptoms increase further in obese women over the age of $54{ }^{24}$ This data supports the theory that obesity over time contributes to low back pain and that weight loss may help prevent the onset of low back pain in obese women. There is no evidence to support the recommendation of weight loss to treat low back pain once the pain is present. 
Table 2. Effects of Obesity on Low Back Pain (LBP)

\begin{tabular}{llll}
\hline Authors & \multicolumn{1}{c}{ Assessment of Obesity } & Results & Effect* (OR [RR]) \\
\hline Brown et al (20) & BMI $>30$ & Increased incidence of LBP & $1.26(1.08-1.48)$ \\
Shiri et al (21) & BMI $>35$ in women aged 24-39 years & Increased incidence of LBP & $1.2(0.8-1.8)$ \\
Tsuritani et al (22) & BMI $>24$ vs BMI $=20-24$ in women & $\begin{array}{c}\text { Increased incidence of LBP and } \\
\text { disability }\end{array}$ & $1.46(0.78-2.47)^{\dagger}$ \\
& $>40$ years old & Increased incidence of LBP and & $1.29(0.74-2.25)^{\ddagger}$ \\
& BMI $>26$ vs BMI $=20-24$ in women & disability & $1.22(0.58-2.57)^{\dagger}$ \\
Guh et al (9) & $>40$ years old & Increased incidence of chronic LBP & $2.44(1.24-4.81)^{\ddagger}$ \\
\hline
\end{tabular}

*All odds ratios (OR) and relative risk (RR) are compared to women with body mass index $(\mathrm{BMI})<25$, unless otherwise noted.

${ }^{\dagger}$ Back pain.

${ }^{\ddagger}$ Disability.

The data supporting the link between obesity and knee $\mathrm{OA}$ in women is even more staggering. The factors underlying the association of obesity with knee OA have not been entirely elucidated. Obesity leads to an excess load on the joint, increased cartilage turnover, increased collagen type 2 degradation products, and increased risk of degenerative meniscal lesions. Although all of these have been theorized to lead to knee OA no causal relationships have been demonstrated to date. ${ }^{25,26}$

Studies have shown that women with a diagnosis of knee OA have an average BMI that is $24 \%$ higher than women without OA. ${ }^{27}$ For every 2 units of BMI gain, the risk of knee OA increases by $36 \%,{ }^{28}$ and 1 category shift downward in BMI from obese to overweight may avoid $19 \%$ of new cases of severe knee pain $^{29}$ (Table 3). The importance of prevention of knee $\mathrm{OA}$ is highlighted by the subsequent burden of surgery. An estimated $69 \%$ of knee replacements in middle-aged women in the United Kingdom have been attributable to obesity. ${ }^{33}$ Dietary weight loss in combination with ex- ercise effectively led to significant improvements in pain and physical function in women with knee OA over 18 months in the Arthritis, Diet, and Activity Promotion Trial. ${ }^{34}$ A separate, randomized clinical trial evaluating rapid weight loss found that a $10 \%$ weight reduction improved function by $28 \%$, with a number needed to treat of $<4$ patients $(95 \% \mathrm{CI}$, 2-9 patients) to achieve a $50 \%$ improvement in the WOMAC score, which is a measure of joint pain, stiffness, and function. ${ }^{35}$

\section{Obesity and Infertility (Including Polycystic Ovary Syndrome)}

Obesity affects fertility throughout a woman's life. The impact of obesity and Polycystic Ovary Syndrome (PCOS) on reproductive function can be attributed to multiple endocrine mechanisms. Abdominal obesity is associated with an increase in circulating insulin levels. This results in increased functional androgen levels (caused by suppression of sex hormone-binding globulin synthesis and increased ovarian androgen production). Chronic el-

Table 3. Effects of Obesity on Knee Osteoarthritis

\begin{tabular}{|c|c|c|c|}
\hline Authors & Assessment of Obesity & Results & Effect $^{*}(\mathrm{OR}[\mathrm{RR}])$ \\
\hline \multirow[t]{2}{*}{ Abbate et al (30) } & $\begin{array}{l}\text { BMI: heaviest quartile vs } \\
\text { lowest quartile }\end{array}$ & Increased diagnosis of knee OA & $5.27(3.05-9.13)$ \\
\hline & $\begin{array}{l}\text { Weight: heaviest quartile vs } \\
\text { lowest quartile }\end{array}$ & Increased diagnosis of knee OA & $5.28(3.05-9.16)$ \\
\hline Grotle et al (31) & $\mathrm{BMI}>30$ & $\begin{array}{l}\text { Increased diagnosis of new knee OA } \\
\text { within } 10 \text { years }\end{array}$ & $2.81(1.32-5.96)$ \\
\hline Holmberg et al (32) & $\mathrm{BMI}$ increase from 23 to 25 & $\begin{array}{l}\text { Increased radiograph diagnosis of } \\
\text { knee OA }\end{array}$ & $1.6(0.9-3.1)$ \\
\hline Liu et al (33) & $\mathrm{BMI}>30$ vs $\mathrm{BMI}<22.5$ & Increased rates of knee replacement & $10.51(7.85-14.08)$ \\
\hline Patterson et al (12) & $\mathrm{BMI}>35$ & Increased rates of knee replacement & 11.7 \\
\hline
\end{tabular}

*All odds ratio $(\mathrm{OR})$ and relative risk $(\mathrm{RR})$ are compared to women with body mass index $(\mathrm{BMI})<25$, unless otherwise noted. OA, osteoarthritis. 
evation of circulating estrogen is caused by aromatization in peripheral adipose tissue. The resulting hyperandrogenism and menstrual cycle abnormalities are clinically manifested in part by anovulatory cycles and subfertility. Additionally, leptin inhibits ovarian follicular development and steroidogenesis and thus may contribute to reproduction difficulties in obese women. ${ }^{36}$

The impact of obesity on reproduction starts at a young age. Obese girls frequently experience the onset of puberty at a younger age than their normal-weight peers. ${ }^{37}$ Between the late 1960s and 1990, during a time of increasing prevalence of childhood obesity, the median age of menarche decreased by approximately 3 months in white girls and 5.5 months in black girls in the United States. ${ }^{37}$

Obesity negatively affects contraception. Older studies have shown that hormonal contraception methods are less effective in obese women. ${ }^{37}$ For example, a retrospective cohort analysis of 2822 person-years of oral contraceptive use suggested that women in the highest quartile of body weight $(\geq 70.5 \mathrm{~kg}$ ) had a $60 \%$ higher risk of failure than women of lower weight. This study also found that the increased risk of failure associated with weight was higher for women using very low-dose or lowdose oral contraceptives. ${ }^{38}$ However, a recent large cohort study in Europe did not show a difference in contraceptive efficacy of oral contraceptive pills based on BMI. ${ }^{39}$

A multicenter study of 1672 healthy, ovulating, sexually active women randomized to receive the transdermal patch Ortho-Evra (Ortho-McNeilJanssen Pharmaceuticals, Inc., Raritan, NJ) for 6 or 13 cycles found a higher rate of failure (pregnancy) in women weighing $>90 \mathrm{~kg}$ (RR 58; 95\% CI, $10.8-310) .{ }^{38}$ Additionally, a study of 1005 women using the levonorgestrol vaginal ring demonstrated higher rates of pregnancy at 1 year for heavier patients $(1.7 \%$ for a $40-\mathrm{kg}$ woman; $9.8 \%$ for an $80-\mathrm{kg}$ woman). ${ }^{37}$ Obesity is a risk factor for technical failure of tubal ligation surgery (OR, 1.7; 95\% CI, 1.2-2.6). ${ }^{40}$ The intrauterine device may be one of the few reliable contraception options whose efficacy does not seem to be affected by BMI. ${ }^{37}$ Product inserts rarely comment on weight-specific guidelines (Table 4).

Although most attention has focused on the impact of obesity on ovulation, other studies suggest a multifactorial impact. A recent national survey in France found that obese women were less likely to access contraceptive health care services and had more unplanned pregnancies. ${ }^{42}$ The US National Longitudinal Survey of Youth prospectively examined the association between body weight in young adulthood and achieved fertility in later life. ${ }^{43}$

\section{Table 4. Manufacturer's Labeling: Weight-Based Precautions for Hormonal Contraception}

\begin{tabular}{ll}
\hline Contraceptive & \multicolumn{1}{c}{ Precautions } \\
\hline $\begin{array}{l}\text { Triphasic oral contraceptive (eg, Ortho Tri Cyclen, } \\
\text { Ortho-McNeil-Janssen Pharmaceuticals, Inc., }\end{array}$ & $\begin{array}{c}\text { Increased body weight and surface area are associated with decreased } \\
\text { hormone concentration (overweight is not listed as a precaution). }\end{array}$ \\
Raritan, NJ) & No weight-specific comments. \\
Monophasic Oral Contraceptive (eg, Loestrin 24 & No weight-specific comments. \\
Fe, Warner Chilcott, Rockaway, NJ) & \\
Progesterone-only contraceptive (eg, Ortho & \\
Micronor, Ortho-McNeil-Janssen & \\
Pharmaceuticals, Inc., & Consider decreased effectiveness $>90 \mathrm{~kg}$ (this is listed as a \\
Raritan, NJ) & precaution). \\
Transdermal contraceptive (eg, Ortho Evra, & \\
Ortho-McNeil-Janssen Pharmaceuticals, Inc., & No weight-specific comments. \\
Raritan, NJ) & \\
Intravaginal ring (eg, Nuva ring, Schering-Plough & Effectiveness not defined because women with $>130 \%$ of ideal body \\
Corp., Kenilworth, NJ) & weight were not studied. However, the hormonal concentration is \\
Implantable progesterone (eg, Implanon, & inversely related to body weight and thus may be less effective in \\
Schering-Plough Corp., Kenilworth, NJ) & overweight patients. \\
& No weight-specific comments. \\
Injectable progesterone (eg, Depo-provera, Pfizer, & No weight-specific comments. \\
Inc., New York, NY) & \\
Hormonal intrauterine device (eg, Mirena, Bayer & \\
HealthCare Pharmaceuticals, Montville, NJ) & \\
\hline
\end{tabular}


Obese young women and men were less likely to have their first child by the age of 47 than were their normal-weight counterparts (for women: RR, 0.69; 95\% CI, 0.61-0.78; for men: RR, 0.75; 95\% CI, 0.66-0.84). This association was partly explained by a lower probability of marriage among obese patients, suggesting both a social and biologic effect on reproductive behavior. ${ }^{43}$

A retrospective cohort study of 22,840 women demonstrated that obesity was associated with reduced fecundity for all weight-adjusted groups of women and persisted for women with regular cycles. ${ }^{44}$ In addition, obesity may alter the quality of oocytes and embryos. ${ }^{45}$ Some studies demonstrate increased female sexual dysfunction in obese patients, whether caused by the physical or psychological impacts of obesity on female sexuality. ${ }^{36}$

Obesity is frequently associated with disturbances in the menstrual cycle. Cross-sectional studies indicate that $30 \%$ to $47 \%$ of overweight and obese women have irregular menses. ${ }^{46}$ PCOS frequently causes menstrual irregularity and is very common among obese women, though the actual prevalence is unclear. Although obesity may amplify the effects of PCOS, it is not a diagnostic criteria for PCOS. Approximately $20 \%$ of women with PCOS are not obese. ${ }^{47}$

Weight loss can improve the fertility of obese women by the return of spontaneous ovulation, thus leading to the recommendation of implementing weight-loss interventions (diet, exercise, medication treatment) as initial management of infertile overweight and obese women. ${ }^{48}$

A systematic review ${ }^{49}$ assessing pregnancy and fertility after bariatric surgery reported that although the available data are not optimal, surgery may have a beneficial influence on fertility. This is supported by the normalization of hormones in PCOS and the correction of abnormal menstrual cycles after surgery.

\section{Obesity and Pregnancy}

An Australian study of more than 14,000 pregnant women found that $34 \%$ were overweight, obese, or morbidly obese. ${ }^{50}$ In a US study of 9 states that included more than 66,000 women, there was a $22 \%$ rate of obesity among pregnant women in 2002 to 2003 , which was up $69 \%$ since $1993 .{ }^{51}$ The subgroups of women with the highest increases in obesity rates were women aged 20 to 29 years, were African American, who had $\geq 3$ children, and who were enrolled in the US Department of Agriculture's Women, Infants, and Children program. ${ }^{51}$ Obesity causes pregnancy complications because of elevated risks of antepartum complications and mechanical difficulties with delivery.

Obesity during pregnancy is related to higher overall health care expenditures, measured by length of stay after delivery and use of other services. The majority of this difference is caused by higher cesarean section rates and higher rates of high-risk obstetric conditions such as diabetes and hypertension. The mean length of stay after delivery was directly correlated to $\mathrm{BMI}^{52}$ (3.6-day stay for women with a normal BMI vs 4.4-day stay for women with a $\mathrm{BMI}>40.0$ ).

Prepregnancy obesity contributes to the development of many pregnancy complications including pregnancy-induced hypertension, preeclampsia, gestational diabetes, c-section, and neonatal death (Table 5). Compounding this finding is the fact that performing a cesarean section is more difficult in obese women.

Rates of fetal anomalies are increased in obese mothers as well, including neural tube defects (OR, 1.87; 95\% CI, 1.62-2.15), spina bifida (OR, 2.24; 95\% CI, 1.86-2.69), cardiovascular anomalies (OR, 1.30; 95\% CI, 1.12-1.51), and cleft lip and palate (OR, 1.20; 95\% CI, 1.03-1.40). ${ }^{61}$ However, maternal obesity was protective for gastroschesis (OR, 0.17; 95\% CI, $0.10-0.30) .{ }^{61}$

Weight loss via bariatric surgery s to decrease many pregnancy complications. A retrospective cohort study that included 585 women who had undergone bariatric surgery found that women who had delivered children after surgery (as compared with women who delivered before surgery) had decreased rates of hypertension during pregnancy (OR, 0.39; 95\% CI, 0.20-0.74) and preeclampsia (OR, 0.20; 95\% CI, 0.09-0.44). ${ }^{62}$ Another study compared women who delivered before surgery to women who delivered after surgery and found decreased rates of diabetes $(17.3 \%$ vs $11 \% ; P=.009)$, hypertensive disorders ( $23.6 \%$ vs $11.2 \% ; P<.001)$, and fetal macrosomia $(7.6 \%$ vs $3.2 \% ; P=.004) .{ }^{63}$

\section{Obesity and Breastfeeding}

Maternal obesity is associated with a decreased intention to breastfeed, decreased initiation of breastfeeding, and decreased duration of breastfeeding. ${ }^{64}$ Some of these effects may be cultural, having to do with one's body image, or physiologic caused by 
Table 5. Effects of obesity on pregnancy outcomes

\begin{tabular}{|c|c|c|}
\hline Condition & Type of Study & Effect* \\
\hline GDM (53) & Meta-analysis & $\begin{array}{l}\text { OR, } 2.14(1.82-2.53)^{\dagger} \\
\text { OR, } 3.56(3.05-4.21)^{\ddagger} \\
\text { OR, } 8.56(5.07-16.04)^{\S}\end{array}$ \\
\hline PIH (54) & Meta-analysis & $\begin{array}{l}\text { OR, } 2.5(2.1-3.0)^{\ddagger} \\
\text { OR, } 3.2(2.6-4.0)^{\S}\end{array}$ \\
\hline C-section (55) & Population-based cohort study & $\begin{array}{l}\mathrm{RR}, 2.6(2.04-2.51)^{\ddagger} \\
\mathrm{RR}, 3.38(2.49-4.57)\end{array}$ \\
\hline Pre-eclampsia (53) & Meta-analysis & $\begin{array}{l}\text { OR, } 1.6(1.1-2.25)^{\ddagger} \\
\text { OR, } 3.3(2.4-4.5)^{\S}\end{array}$ \\
\hline Preeclampsia (56) & Retrospective cohort study & OR, $7.2(4.7-11.2)^{\S}$ \\
\hline Induction of labor (56) & Retrospective cohort study & OR, $1.8(1.3-2.5)^{\S}$ \\
\hline Postpartum hemorrhage (56) & Population-based cohort study & OR, $1.5(1.3-1.7)^{\|}$ \\
\hline Preterm delivery (<33 weeks) (56) & Population-based cohort study & OR, $2.0(1.3-2.9)^{\|}$ \\
\hline Stillbirth (57) & Systematic review and meta-anaylsis & $\begin{array}{l}\text { OR, } 1.47^{\dagger} \\
\mathrm{RR}, 2.07^{\|}\end{array}$ \\
\hline Stillbirth (58) & Population-based cohort study & OR, $2.8(1.5-5.3)^{\|}$ \\
\hline Neonatal death (58) & Population-based cohort study & OR, $2.6(1.2-5.8)^{\|}$ \\
\hline
\end{tabular}

*All odds ratio (OR) and relative risk (RR) are compared to normal weight pregnant women (body mass index [BMI] 18-25). Values in parentheses indicate $95 \% \mathrm{CI}$.

${ }^{\dagger}$ BMI 25-30.

${ }^{\ddagger}$ BMI 30-35.

${ }^{\S} \mathrm{BMI}>35$.

${ }$ BMI > 30. GDM, gestational diabetes mellitus. PIH, pregnancy-induced hypertension.

metabolic and hormonal effects of adipose tissue (ie, decreased milk supply). However, obesity may also be related to some confounders such as more pregnancy complications, which also have negative effects on breastfeeding rates.

A large study in the United Kingdom asked approximately 11,000 women at 32 weeks' gestation about their level of concern regarding their shape and weight. After adjusting for multiple variables, those with "marked concern" for both were significantly less likely to intend to breastfeed. ${ }^{65}$ Another smaller study done in the United States among 114 women found that obese women intended to breastfeed for a significantly shorter period of time than other women. ${ }^{66}$

Several studies have demonstrated decreased breastfeeding initiation rates among obese women compared with normal-weight women. ${ }^{64,67-70}$ One chart review of 1109 white mother-baby dyads found that the overweight and obese mothers were more likely to quit breastfeeding at the time of discharge from the hospital compared with mothers who were normal weight $(12.2 \%$ vs $4.3 \%){ }^{67}$

Obese women are at greater risk of a delay in milk production, which may be related to decreased rates of breastfeeding initiation. One study found that obese women had lower prolactin responses to suckling in the first week compared with normalweight women. ${ }^{71}$ There is also evidence that excess body fat may impair mammary gland development before conception and during pregnancy by hormonal and metabolic effects. ${ }^{72}$

Maternal obesity is also associated with a shortened duration of breastfeeding. ${ }^{64,69,70,73,74}$ A Danish study of nearly 38,000 women observed that the greater the prepregnant BMI, the earlier the termination of breastfeeding. ${ }^{73}$ There is no data looking at future breastfeeding rates with subsequent pregnancies after weight loss.

\section{Obesity and Depression}

Population-based studies looking at the association between obesity and depression have yielded inconsistent results, with only some finding an association. ${ }^{75-78}$ The difference between sexes is similarly inconsistent. Some studies found an association between obesity and higher rates of depression in women but not in men ${ }^{79,81}$; others reported inverse associations between obesity and depression in both women and men. ${ }^{81}$

Most recently, data from the third National Health and Nutrition Examination Survey (19881994) showed that obesity was associated with pastmonth depression in women (OR, 1.82; 95\% CI, 
1.01-3.3) but not in men (OR, 1.73; 95\% CI, 0.565.37). ${ }^{82}$ This relationship was stronger when obesity was stratified by severity. One 5 -year prospective study following a cohort of 2298 persons from Alameda County, CA, showed that the obese were at increased risk of depression (prevalence: OR, 2.16; 95\% CI, 1.47-3.19; incidence: OR, 2.11; 95\% CI, 1.29-3.47) but there was no effect of sex on this association. ${ }^{77}$

Although many social, psychological, and cultural factors likely contribute to the development of depression in obese women, one explanation argues that the stigma toward obese individuals in American society leads to low self-esteem and ultimately depression. Thus, in communities where a higher weight is acceptable, less psychological impact is observed. Another theory argues that obesity is not stressful per se, but the pressure to fit a norm and continued dieting leads to depression. ${ }^{83}$

\section{Obesity and Cancer in Women General}

There is mounting evidence that obesity is a risk factor for developing gynecologic and breast cancers and that a higher BMI may also adversely impact survival. Obese women with cancer may have decreased survival because of later screening, comorbid illnesses, or poorer response to treatment. Obese women have increased surgical and possibly radiation complications. In addition, there is no current consensus regarding appropriate chemotherapy dosing for the obese patient. ${ }^{84}$ The increased levels of endogenous estrogen contribute to higher risk of several types of cancer. ${ }^{85,86}$

\section{Endometrial Cancer}

Endometrial carcinoma is strongly related to obesity. In premenopausal women, anovulation or oligoovulation that is associated with PCOS results in an endometrium that is chronically exposed to unopposed estradiol. This causes proliferation and the potential for neoplastic changes. Additionally, in premenopausal and postmenopausal obese women, increased insulin and androgens decrease the production of sex hormone-binding globulin. This leads to more and unregulated bioavailable estrogens in postmenopausal women.

In 2001 the International Agency for Research on Cancer found that there was convincing evidence based on large cohort and case-control stud- ies that obesity is associated with a 2- to 3 -fold risk in endometrial cancer. ${ }^{84,87}$ Epidemiologic data has found a 2- to 5-fold increased risk of developing endometrial carcinoma in premenopausal and postmenopausal women, and obesity has been associated with at least $40 \%$ of the incidence of endometrial cancer. ${ }^{86,88,89}$ Mortality from uterine cancer also seems to increase with BMI. A prospective study through the American Cancer Society following 495,477 women found that those with a BMI $>40$ had an endometrial cancer mortality increased RR of 6.25 (95\% CI, 3.75-10.42.). ${ }^{85,90}$

\section{Ovarian Cancer}

The data linking ovarian cancer and obesity has been mixed. ${ }^{91-93}$ The rationale for an increased risk of ovarian cancer in obese women focuses on the hormonal impact of obesity. In 2001, the International Agency for Research on Cancer group found that the "evidence from the relatively few studies on body weight and ovarian cancer has been inconsistent and does not allow any conclusion to be drawn on a possible association." ${ }^{87}$ If some subtypes of ovarian cancer are hormonally responsive, it seems logical to assume that unopposed estrogen could increase the risk of these cancers in obese women. ${ }^{84}$

\section{Cervical Cancer}

Several studies have shown both increased incidence and mortality from cervical cancer among obese women. This relationship may be because of decreased screening compliance among obese women. ${ }^{84}$ Obesity likely plays a more prominent role in the development of cervical adenocarcinoma than squamous cell carcinoma secondary to the role of additional estrogenic hormones. ${ }^{94}$ Disparities in cervical cancer screening by body weight persist for women who are severely obese. Obese white women may put off cervical cancer screening because of embarrassment or discomfort. Physicians recommend $\mathrm{Pa}$ panicolaou smears for obese women at the same rate as for normal weight women. ${ }^{95,96}$

\section{Breast Cancer}

There is a well-established link between obesity and postmenopausal breast cancer. ${ }^{97}$ It is hypothesized that this is because of an increase in the serum concentration of bioavailable estradiol. ${ }^{98}$ In 1997, a meta-analysis analyzed 51 studies, including 52,705 women with breast cancer and 108,411 
women without breast cancer, and found that the strength of the estrogenic risk attenuated by obesity is stronger than with hormone replacement therapy. In fact, hormone replacement therapy does not increase the risk of breast cancer in obese, postmenopausal women (RR, 1.02 for BMI $>25$ $\mathrm{kg} / \mathrm{m}^{2}$ ), though it is a significant risk for breast cancer in normal-weight women (RR, 1.73). ${ }^{99,100}$

Several meta-analyses, systematic reviews, and large cohort studies have shown obesity worsens breast cancer mortality. Obese women also have greater disease morbidity, including a higher recurrence rate, increased contralateral breast cancer, wound complications after breast surgery, and lymphedema. ${ }^{101}$ Poorer outcomes associated with breast cancer may be related to more aggressive disease at diagnosis, a higher likelihood of treatment failure, and a higher likelihood of delayed detection. Morbidly obese women are significantly less likely to report recent mammography. This is particularly true for white women. ${ }^{102,103}$ Obesity may also promote more rapid growth of metastatic disease because of impaired cellular immunity. In addition, the hyperinsulinemia found in some obese women may promote mammary carcinogenesis by increasing the levels of insulin-like growth factor and leptin, which have a synergistic effect with estrogen on mammary epithelial cells by promoting angiogenesis. ${ }^{101}$

\section{Weight Loss and Cancer}

Studies evaluating the long-term impact of weight loss on cancer risk among women have shown mixed results. In one large US study, cancer incidence and mortality data were compared between 6596 patients who had gastric bypass (between 1984 and 2002) and 9442 morbidly obese persons who had not had surgery. This study showed decreased overall cancer rates in women $(P<.0004)$, with the strongest impact on endometrial cancer $(P<.0001)$ and with less significant impacts on premenopausal and postmenopausal breast cancer $(P<.54)$, cervical cancer $(P<.78)$, and ovarian cancer $(P<.19) .{ }^{104}$ A large Swedish study followed 13,123 obesity surgery patients and found no overall decrease in obesity-related cancers compared with the baseline incidence among obese individuals. No statistically significant trends were found for breast cancer $(P<.60)$ or endometrial cancer $(P<.83)$ over time. Therefore, efforts directed toward prevention of obesity might be more helpful than weight reduction in attempts to reduce the incidence of obesityrelated cancer. ${ }^{105}$

\section{Conclusion}

Obesity is becoming more prevalent and has wideranging effects on a variety of women's health issues. Clinicians should counsel all women about the broad negative effects of obesity and the importance of controlling weight to prevent negative outcomes.

\section{References}

1. World Health Organization. Global strategy on diet, physical activity and health. Obesity and overweight. 2010. Available at: http://www. who.int/dietphysicalactivity/publications/facts/ obesity/en/. Accessed November 11, 2010.

2. Hedley AA, Ogden CL, Johnson CL, Carroll MD, Curtin LR, Flegal KM. Prevalence of overweight and obesity among US children, adolescents, and adults, 1999-2002. JAMA 2004;291:2847-50.

3. National Heart, Lung, and Blood Institute. Guidelines on overweight and obesity: the electronic textbook. Assessment of weight and body fat. Available at: http:// www.nhlbi.nih.gov/guidelines/obesity/e_txtbk/txgd/ 411.htm. Accessed June 10, 2010.

4. Bray GA. Risks of obesity. Endocrinol Metab Clin N Ám 2003;32:787-804.

5. Gallagher EJ, LeRoith D, Karnieli E. The metabolic syndrome-from insulin resistance to obesity and diabetes. Endocrinol Metab Clin North Am 2008;37:559-79, vii.

6. Grundy SM, Brewer HB Jr, Cleeman JI, et al. Definition of metabolic syndrome: Report of the National Heart, Lung, and Blood Institute/American Heart Association conference on scientific issues related to definition. Circulation 2004;109:433-8.

7. Maggio CA, Pi-Sunyer FX. Obesity and type 2 diabetes. Endocrinol Metab Clin N Am 2003;32: 805-22.

8. Carey VJ, Walters EE, Colditz GA, et al. Body fat distribution and risk of non-insulin-dependent diabetes mellitus in women. The Nurses' Health Study. Am J Epidemiol 1997;145:614-9.

9. Guh DP, Zhang W, Bansback, Amarsi Z, Birmingham CL, Anis AH. The incidence of comorbidities related to obesity and overweight: a systematic review and meta-analysis. BMC Public Health 2009; 9:88.

10. Buchwald H, Estok R, Fahrbach K, et al. Weight and type 2 diabetes after bariatric surgery: systematic review and meta-analysis. Am J Med 2009;122: 248-56.

11. Weiss AM. Cardiovascular disease in women. Prim Care 2009;36:73-102. 
12. Patterson RE, Frank LL, Kristal AR, White E. A comprehensive examination of health conditions associated with obesity in older adults. Am J Prev Med 2004;27:385-90.

13. Anand SS, Islam S, Rosengren A, et al. Risk factors for myocardial infarction in women and men: insights form the INTERHEART study. Eur Heart J 2008;29:932-40.

14. Zhang C, Rexrode KM, van Dam RM, Li TL, Hu FB. Abdominal obesity and the risk of all-cause, cardiovascular, and cancer mortality. Circulation 2008;117:1658-67.

15. Buchwald H, Avidor Y, Braunwald E, et al. Bariatric surgery: a systematic review and meta-analysis. JAMA 2004;292:1724-37.

16. National Center for Chronic Disease Prevention and Health Promotion. Arthritis related statistics 2006. Available at http://www.cdc.gov/arthritis/data_statistics/ arthritis_related_stats.htm

17. Like M, Solovieva S, Lamminen A, et al. Disc degeneration of the lumbar spine in relation to overweight. Int J Obes 2005;29:903-8.

18. Hangai M, Kaneoka K, Kuno S, et al. Factors associated with lumbar intervertebral disc degeneration in the elderly. Spine J 2008;8:732-40.

19. Lake JK, Power C, Cole TJ. Back pain and obesity in the 1958 British birth cohort: cause or effect? J Clin Epidemiol 2000;53:245-50.

20. Brown WJ, Mishra G, Kenardy J, Dobson A. Relationships between body mass index and well-being in young Australian women. Int J Obes 2000; 24:1360-8.

21. Shiri R, Solovieva S, Husgafvel-Pursianinen K, et al. The association between obesity and the prevalence of low back pain in young adults: the Cardiovascular Risk in Young Finns Study. Am J Epidemiol 2008;167:1110-9.

22. Tsuritani I, Honda R, Noborisaka Y, Ishida M, Ishizaki M, Yamada Y. Impact of obesity on musculoskeletal pain and difficulty of daily movements in Japanese middle-aged women. Maturitas 2002; 42:23-30.

23. Kostova V, Koleva M. Back disorders (low back pain, cervicobrachial and lumbosacral radicular syndromes) and some related risk factors. J Neurol Sci 2001;192:17-25.

24. Bener A, Alwash R, Gaber T, Lovasz G. Obesity and low back pain. Coll Antropol 2003;27:95-104.

25. Niu J, Zhang YQ, Torner J, et al. Is obesity a risk factor for progressive radiographic knee osteoarthritis? Arthritis Rheum 2009;61:329-35.

26. Reijman M, Pols HAP, Bergink AP, et al. Body mass index associated with onset and progression of osteoarthritis of the knee but not of the hip: The Rotterdam Study. Ann Rheum Dis 2007;66: 158-62.

27. Sowers MF, Yosesf M, Jamadar D, Jacobson J, Karvonen-Gutierrez C, Jaffe M. BMI vs. body composition and radiographically defined osteoarthritis of the knee in women: a 4-year follow-up study. Osteoarthritis Cartilage 2008;16:367-72.

28. Lementowski PW, Zelicof SB. Obesity and osteoarthritis. Am J Orthop 2008;37:148-51.

29. Jinks C, Jordan K, Croft P. Disabling knee painanother consequence of obesity: results from a prospective cohort study. BMC Public Health 2006;6: 258-65.

30. Abbate LM, Stevens J, Schwartz TA, Renner JB, Helmick CG, Jordan JM. Anthropometric measures, body composition, body fat distribution, and knee osteoarthritis in women. Obesity 2006; $14: 1274-81$.

31. Grotle M, Hagen KB, Natvig B, Dahl FA, Kvien TK. Obesity and osteoarthritis in knee, hip and/or hand: an epidemiological study in the general population with 10 years follow-up. BMC Musculoskelet Disord 2008;9:132-6.

32. Holmberg S, Thelin A, Thelin N. Knee osteoarthritis and body mass index: a population-based case-control study. Scand J Rheumatol 2005;34:59-64.

33. Liu B, Balkwill A, Banks E, Cooper C, Green J, Beral V. Relationship of height, weight and body mass index to the risk of hip and knee replacements in middle-aged women. Rheumatology 2007;46:861-7.

34. Rejeski WJ, Focht BC, Messier SP, Morgan T, Pahor M, Penninx B. Obese, older adults with knee osteroarthritis: weight loss, exercise, and quality of life. Health Psychol 2002;21:419-26.

35. Christensen R, Astrup A, Bliddal H. Wight loss: the treatment of choice for knee osteroarthritis? A randomized trial. Osteoarthritis Cartilage 2005;13:20-7.

36. Shah M. Obesity and sexuality in women. Obstet Gynecol Clin N Am 2009;36:347-60.

37. Lash MM, Armstrong A. Impact of obesity on women's health. Fertil Steril 2009;91:1712-6.

38. Holt VL, Cushing-Haugen KL, Daling JR. Body weight and risk of oral contraceptive failure. Obstet Gynecol 2002;99:820-7.

39. Dinger JC, Cronin M, Möhner S, Schellschmidt I, Minh TD, Westhoff C. Oral contraceptive effectiveness according to body mass index, weight, age, and other factors. Am J Obstet Gyn 2009;201:263.e1-9.

40. Smallwood GH, Meador ML, Lenihan JP, Shangold GA, Fisher AC, Creasy GW. Efficacy and safety of a transdermal contraceptive system. Obstet Gynecol 2001;98:799-805.

41. Jamieson DJ, Hillis SD, Duerr A, Marchbanks PA, Costello C, Peterson H. Complications of interval laparoscopic tubal sterilization: findings from the United States Collaborative Review of Sterilization. Obstet Gynecol 2000;96:997-1002.

42. Bajos N, Wellings K, Laborde C, Moreau C. Sexuality and obesity, a gender perspective: results 
from French national random probability survey of sexual behaviors. BMJ 2010;340:c2573.

43. Jokela M, Elovainio M, Kivimaki M. Lower fertility associated with obesity and underweight: the US National Longitudinal Survey of Youth. Am J Clin Nutr 2008;88:886-93.

44. Yilmaz N, Kilic S, Kanat-Pektas M, Gulerman C, Mollamahmutoglu L. The relationship between obesity and fecundity. J Womens Health (Larchmt) 2009;18:633-6.

45. Robker R. Evidence that obesity alters the quality of oocytes and embryos. Pathophysiology 2008;15: 115-21.

46. The Practice Committee of American Society for Reproductive Medicine. Obesity and reproduction: an educational bulletin. Fertil Steril 2008;90(5 Suppl):S21-9.

47. ACOG Committee on Practice Bulletins-Gynecology. ACOG Practice Bulletin No. 108: polycystic ovary syndrome. Obstet Gynecol 2009;114:936-49.

48. Norman RJ, Noakes M, Wu R, Davies MJ, Moran $\mathrm{L}$, Wang JX. Improving reproductive performance in overweight/obese women with effective weight management. Hum Reprod Update 2004; 10:267-80.

49. Maggard MA, Yermilov I, Li Z, et al. Pregnancy and fertility following bariatric surgery: a systematic review. JAMA 2008;300:2286-96.

50. Callaway LK, Prins JB, Chang AM, McIntyre HD. The prevalence and impact of overweight and obesity in an Australian obstetric population. Med J Aust 2006;184:56-9.

51. Kim SY, Dietz PM, England L, Morrow B, Callaghan WM. Trends in pre-pregnancy obesity in nine states, 1993-2003. Obesity 2007;15:986-93.

52. Chu SY, Bachman DJ, Callaghan WM, et al. Association between obesity during pregnancy and increased use of health care. N Engl J Med 2008;358: 1444-53.

53. Chu SY, Callaghan WM, Kim SY, et al. Maternal obesity and risk of gestational diabetes mellitus. Diabetes Care 2007;30:2070-6.

54. Weiss JL, Malone FD, Emig D, et al. Obesity, obstetric complications and caesarean delivery rate-a population-based screening study. Am J Obstet Gynecol 2004;190:1091-7.

55. Poobalan AS, Aucott LS, Gurung T, Smith WC, Bhattacharya S. Obesity as an independent risk factor for elective and emergency caesearean delivery in nulliparous women-systematic review and meta-analysis of cohort studies. Obes Rev 2009;10:28-35.

56. Bhattacharya S, Campbell DM, Liston WA, Bhattacharya S. Effect of body mass index on pregnancy outcomes in nulliparous women delivering singleton babies. BMC Public Health 2007;7:168.

57. Chu SY, Kim SY, Lau J, et al. Maternal obesity and risk of stillbirth: a meta-analysis. Am J Obstet Gynecol 2007;197:223-8.
58. Kristensen J, Vestergaard M, Wisborg K, Kesmodel U, Secher NJ. Pre-pregnancy weight and the risk of stillbirth and neonatal death. BJOG 2005; 112:403-8.

59. Stothard KJ, Tennant PW, Bell R, Rankin J. Maternal overweight and obesity and the risk of congenital anomalies: a systematic review and metaanalysis. JAMA 2009;301:636-50.

60. Bennett WL, Gilson MM, Jamshidi R, et al. Impact of bariatric surgery on hypertensive disorders in pregnancy: retrospective analysis of insurance claims data. BMJ 2010;340:c1662.

61. Weintraub AY, Levy A, Levi I, Mazor M, Wiznitzer A, Sheiner E. Effect of bariatric surgery on pregnancy outcome. Int J Gynaecol Obstet 2008;103:246-51.

62. Amir LH, Donath S. A systematic review of maternal obesity and breastfeeding intention, initiation and duration. BMC Pregnancy Childbirth 2007;7:9.

63. Barnes J, Stein A, Smith T, Pollock JI. Extreme attitudes to body shape, social and psychological factors and a reluctance to breast feed. ALSPAC Study Team. Avon Longitudinal Study of Pregnancy and Childhood. J R Soc Med 1997;90:551-9.

64. Hilson JA, Rasmussen KM, Kjolhede CL. High prepregnant body mass index is associated with poor lactation outcomes among white, rural women independent of psychosocial and demographic correlates. J Hum Lact 2004;20:18-29.

65. Hilson, JA, Rasmussen KM, Kuolhede CL. Maternal obesity and breast-feeding success in a rural population of white women. Am J Clin Nutr 1997; 66:1371-8.

66. Kugyelka JG, Rasmussen KM, Frongillo EA. Maternal obesity is negatively associated with breastfeeding success among Hispanic but not black women. J Nutr 2004;134:1746-53.

67. Li R, Jewell S, Grummer-Strawn L. Maternal obesity and breast-feeding practices. Am J Clin Nutr 2003;77:931-6.

68. Oddy WH, Li J, Landsborough L, Kendall GE, Henderson S, Downie J. The association of maternal overweight and obesity with breastfeeding duration. J Pediatr 2006;149:185-91.

69. Rasmussen KM, Kjolhede CL. Prepregnant overweight and obesity diminish the prolactin response to suckling in the first week postpartum. Pediatrics 2004;113:e465-71.

70. Rasmussen KM. Association of maternal obesity before conception with poor lactation performance. Annu Rev Nutr 2007;27:103-21.

71. Baker JL, Michaelsen KF, Sorensen TIA, Rasmussen KM. High prepregnant body mass index is associated with early termination of full and any breastfeeding in Danish women. Am J Clin Nutr 2007;86:404-11.

72. Liu J, Smith MG, Dobre MA, Ferguson JE. Maternal obesity and breast-feeding practices among white and black women. Obesity 2010;18:175-82. 
73. Faith MS, Matz PE, Jorge MA. Obesity-depression associations in the population. J Psychosom Res 2002;53:935-42.

74. Roberts RE, Kaplan GA, Shema SJ, Strawbridge WJ. Are the obese at greater risk for depression? Am J Epidemiol 2000;152:163-70.

75. Roberts RE, Strawbridge WJ, Deleger S, Kaplan GA. Are the fat more jolly? Ann Behav Med 2002; 24:169-80.

76. Palinkas LA, Wingard DL, Barrett-Connor E. Depressive symptoms in overweight and obese older adults: a test of the "jolly fat" hypothesis. J Psychosom Res 1996;40:59-66.

77. Istvan J, Zavela K, Weidner G. Body weight and psychological distress in NHANES I. Int J Obes Relat Metab Disord 1992;16:999-1003.

78. Carpenter KM, Hasin DS, Allison DB, Faith MS. Relationships between obesity and DSM-IV major depressive disorder, suicide ideation, and suicide attempts: results from a general population study. Am J Pub Health 2000;90:251-7.

79. Crisp AH, McGuiness B. Jolly fat relation between obesity and psychoneurosis in general population. BMJ 1976;1:7-9.

80. Onyike CU, Crum RM, Lee HB, Lykestos CG, Eaton WW. Is obesity associated with major depression? Results from the Third National Health and Nutrition Examination Survey. Am J Epidemiol 2003;158:1139-47.

81. Ross CE. Overweight and depression. J Health Soc Behav 1994;35:63-79.

82. Modesitt SC, van Nagell JR. The impact of obesity on the incidence and treatment of gynecologic cancers: a review. Obstet Gyn Surv 2005;60:683-92.

83. Hoskins WJ, Perez CA, Young RC. Principles and practice of gynecologic oncology. 2nd ed. Philadelphia, PA: Lippincott Williams \& Wilkins; 2009.

84. Kaaks R, Lukanova A, Kurzer MS. Obesity, endogenous hormones, and endometrial cancer risk: a synthetic review. Cancer Epidemiol Biomarkers Prev 2002;11:1531-43.

85. Vaino H, Bianchini F. IARC handbook of cancer prevention: volume 6: weight control and physical activity. Geneva, Switzerland: World Health Organization Press; 2002.

86. Chang S, Lacey JV, Brinton LA, et al. Lifetime weight history and endometrial cancer risk by type of menopausal hormone use in the NIH-AARP diet and health study. Cancer Epidemiol Biomarkers Prev 2007;16:723-30.

87. Purdie DM, Green AC. Epidemiology of endometrial cancer. Best Pract Res Clin Obstet Gynaecol 2001;15:341-54.

88. Calle EE, Rodriguez C, Walker-Thurmond K, Thun MJ. Overweight, obesity and mortality from cancer in a prospectively studied cohort of US adults. N Engl J Med 2003;348:1625-38.
89. Rodriguez C, Calle EE, Gakhrabadi-Shokoohi D, Jacobs EJ, Thun MJ. Body mass index, height, and the risk of ovarian cancer mortality in a prospective cohort of postmenopausal women. Cancer Epidemiol Biomarkers Prev 2002;11:822-8.

90. Schouten LJ, Rivera C, Hunter DJ, et al. Height, body mass index, and ovarian cancer: a pooled analysis of 12 cohort studies. Cancer Epidemiol Biomarkers Prev 2008;17:902-12.

91. Leitzmann MF, Koebnick C, Danforth KN, et al. Body mass index and risk of ovarian cancer. Cancer 2009;115:812-22.

92. Lacey JV, Swanson CA, Brinton LA, et al. Obesity as a potential risk factor for adenoarcinomas and squamous cell carcinomas of the uterine cervix. Cancer 2003;98:814-21.

93. Wee CC, Phillips RS, McCarthy EP. BMI and cervical cancer screening among white, AfricanAmerican, and Hispanic women in the United States. Obes Res 2005;13:1275-80.

94. Maruthur NM, Bolen SD, Brancati FL, Clark JM. The association of obesity and cervical cancer screening: a systematic review and meta-analysis. Obesity 2009;17:375-81.

95. Renehan AG, Tyson M, Egger M, Heller RF, Zwahlen M. Body-mass index and the incidence of cancer: a systemataic review and meta-analysis of prospective observational studies. Lancet 2008;371: 569-78.

96. Key TJ, Appleby PN, Reeves GK, et al. Body mass index, serum sex hormones, and breast cancer risk in postmenopausal women. J Natl Cancer Inst 2003;95:1218-26.

97. Kuhl H. Breast cancer risk in the WHI study: the problem of obesity. Maturitas 2005;51:83-97.

98. Breast cancer and hormone replacement therapy: collaborative reanalysis of data from 51 epidemiological studies of 52,705 women with breast cancer and 108,411 women without breast cancer. Collaborative Group on Hormonal Factors in Breast Cancer. Lancet 1997;350:1047-59.

99. Carmichael AR. Obesity and prognosis of breast cancer. Obes Rev 2006;7:333-40.

100. Maruthur NM, Bolen S, Brancati FL, Clark JM. Obesity and mammography: a systematic review and meta-analysis. J Gen Intern Med 2009;24:665-77.

101. Cohen SS, Palmieri RT, Nyante SJ, et al. Obesity and screening for breast, cervical, and colorectal cancer in women: a review. Cancer 2008;112:1892904.

102. Adams TD, Stroup AM, Gress RE, et al. Cancer incidence and mortality after gastric bypass surgery. Obesity (Silver Spring) 2009;17:796-802.

103. Plecka Östlund M, Lu Y, Lagergren J. Risk of obesity-related cancer after obesity surgery in a population-based cohort study. Ann Surg 2010. Epub ahead of print. 